\title{
Relationship between platelet activating factor acetylhydrolase activity and apolipoprotein B levels in patients with peanut allergy
}

\author{
Boris Perelman, Areej Adil and Peter Vadas*
}

\begin{abstract}
Background: Platelet-activating factor (PAF) is a highly potent phospholipid mediator responsible for the life-threatening manifestations of anaphylaxis. PAF acetylhydrolase (PAF-AH) inactivates PAF and protects against severe anaphylaxis whereas deficiency of PAF-AH predisposes to severe or fatal anaphylaxis. Determinants of PAF-AH activity have not been studied in patients with peanut allergy.

Objectives: To determine whether plasma PAF-AH activity in patients with peanut allergy is related to formation of circulating complexes with apolipoprotein B (apoB) the main surface protein on low density lipoprotein particles.

Methods: Plasma PAF-AH activity and apoB concentrations were measured in 63 peanut allergic patients (35 boys, 28 girls, ages 2 - 19 years). ApoB concentration was measured immunoturbidimetrically using goat anti-human apoB. The correlation between PAF-AH activity and apoB concentration was determined.

Results: A positive correlation was found between PAF-AH activity and apoB concentration $\left(r^{2}=0.59, P<0.0001\right)$.

Conclusion: In peanut allergic patients, PAF-AH activity strongly correlates with apoB concentration, suggesting the presence of circulating PAF-AH- lipoprotein complexes.
\end{abstract}

Keywords: Anaphylaxis, Platelet-activating factor (PAF), PAF-acetylhydrolase (PAF-AH), Low density lipoprotein (LDL), Apolipoprotein B (apoB)

\section{Findings}

Deficiency of platelet activating factor acetylhydrolase (PAF-AH) predisposes to severe or fatal anaphylaxis. PAF-AH correlates with apolipoprotein $\mathrm{B}$ in peanut allergic patients, suggesting that formation of PAF-AHlipoprotein complexes is an important determinant of PAF-AH activity.

\section{Introduction}

Platelet-activating factor (PAF) is one of the most potent lipid messengers involved in inflammatory events. PAF has been implicated in mediating the life-threatening manifestations of anaphylaxis including hypotension, increased vascular permeability, and severe bronchoconstriction $[1,2]$. The association of PAF with severe

\footnotetext{
* Correspondence: vadasp@smh.ca
Division of Allergy and Clinical Immunology, Department of Medicine, St.

* Correspondence: vadasp@smh.ca
Division of Allergy and Clinical Immunology, Department of Medicine, St. Michael's Hospital, University of Toronto, 30 Bond St., M5B 1 W8 Toronto, ON, Canada
}

or fatal anaphylaxis has been observed in both animal models and in humans. PAF receptor antagonists protected against fatal anaphylaxis in experimental animals $[3,4]$. PAF receptor knockout mice were resistant to fatal anaphylaxis as compared to wild type mice [5]. In humans, PAF levels correlated more strongly with anaphylaxis severity than did histamine or tryptase [6,7]. In human vascular smooth muscle cells, epinephrine blocked PAF mediated signaling, likely by phosphorylation of the PAF receptor [8].

Serum PAF concentrations are rigorously controlled by tight regulation of biosynthesis and degradation. Cells synthesize and secrete PAF de novo only when stimulated. De-acetylation of PAF at the sn-2 position terminates the biologic activity of PAF, with formation of the inactive metabolite, lysoPAF [9]. The de-acetylation reaction is catalyzed by PAF acetylhydrolase (PAF-AH), a calciumindependent phospholipase A2 [10]. PAF-AH activity is an important determinant of the circulating half-life of 
PAF. The half-life of exogenous PAF is significantly longer in sera of PAF-AH deficient persons $[6,11]$. Conversely, increasing concentrations of PAF-AH correlate with more rapid inactivation of PAF [6]. Patients deficient in PAF-AH have been shown to be at increased risk of severe or fatal anaphylaxis, although the mechanisms regulating PAF-AH activity in patients at risk for fatal anaphylaxis have not yet been defined [6].

The circulating form of PAF-AH is also known as lipoprotein-associated phospholipase $\mathrm{A}_{2}$. In human plasma, $70 \%$ of PAF-AH circulates in fully active form as a complex with low density lipoprotein (LDL) and the remainder in high density lipoproteins (HDL) [12]. Plasma PAF-AH concentration directly correlates with LDL cholesterol concentrations in male subjects [13], such that changes in LDL concentration are reflected by corresponding changes in PAF-AH concentration. The catalytic activity of PAF-AH is regulated by its association with LDL, as lowering LDL in plasma increases the half-life of PAF [13]. The halflife of PAF is also prolonged in patients with abetalipoproteinemia, a condition characterized by deficiency of apolipoprotein-containing lipoproteins, including LDL [13]. Drugs that lower LDL levels lower PAF-AH activity as well. For example, rabbits treated with simvastatin for two months showed decreased PAF-AH activity as compared with control rabbits [14]. Although PAF-AH predominantly circulates in the blood associated with LDL in normolipidemic individuals, the relative proportion of PAF-AH associated with LDL and HDL can be affected by various factors [13]. The relationship between PAF-AH activity and LDL concentrations has not been studied in patients with a history of peanut allergy.

Apolipoprotein B (apoB) is complexed mainly with LDL and is a good surrogate measure of LDL concentration [15]. Generally, more than $90 \%$ of plasma apoB is on LDL particles (the remainder on LDL precursors). Each LDL precursor particle has exactly one molecule of apoB on its surface, which remains there during shrinkage to an LDL particle [16]. We undertook this study to investigate whether there is a correlation between PAF-AH activity and apolipoprotein $\mathrm{B}$ concentrations in patients with peanut allergy.

\section{Methods}

\section{Study design}

Apolipoprotein B concentrations and PAF-AH activity were measured in 63 children with peanut allergy ( 35 boys and 28 girls; mean age, $6.5 \pm 3.9$ years; range $2-19$ years). These children had previous allergic reactions to peanut characterized only by urticaria and/or angioedema with positive skin tests to peanut protein of $\geq 8 \mathrm{~mm}$ wheal diameter and/or peanut-specific $\operatorname{IgE} \geq 14 \mathrm{kU} / \mathrm{L}$.

The demographics and diagnostic criteria for this patient cohort were reported previously [6]. Informed consent was obtained from all patients or their parents or guardians. This study was approved by the Research Ethics Board of St. Michael's Hospital.

\section{Reagents}

Radiolabelled PAF (1-O-hexadecyl-2-acetyl-H]-sn-glycero3-phosphoholine, $499.5 \mathrm{Gbq} / \mathrm{mmol}$ ) was purchased from NEN Life Science Products (Boston, MA). Unlabelled PAF and lyso-PAF were from BIOMOL (Brockville, Ontario). 1-palmitoyl-2-arachidonoyl-sn-glycero-3-phosphocholine, egg yolk phosphatidylcholine, pefabloc (4-2-[aminoethyl] benzenesulfonyl fluoride) and apolipoprotein-B kit were obtained from Sigma (Oakville, Ontario). Pre-coated TLC plates SILICA GEL 60 (layer thickness $0.25 \mathrm{~mm}, 20 \times$ $20 \mathrm{~cm}$ ) were from Merck, Germany. All other chemicals were from Sigma.

\section{Measurement of Apolipoprotein-B concentrations}

Plasma PAF-AH activity has been shown to correlate strongly with the plasma concentration of low density lipoproteins (LDL) [10]. PAF-AH activity was measured as a function of apoB concentration. Human apoB concentration was measured immunoturbidimetrically using goat anti-human apoB (Sigma), which forms an insoluble complex resulting in turbidity of the assay mixture. Turbidity was measured spectrophotometrically at $340 \mathrm{~nm}$. The concentration of apoB in the samples was determined from a calibration curve using multiple-level apoB calibrators (Sigma) at 5 different concentrations, ranging from 0-182 mg/dl.

\section{Measurement of PAF-AH activity}

PAF-acetylhydrolase activity was measured according to the method of Miwa et al [2] as modified by Vadas et al [6].

\section{Results}

PAF-AH and apoB concentrations in patients with peanut allergy

PAF-AH activity and apoB concentrations were measured in 63 peanut allergic patients. The relationship between PAF-AH activity, peanut-specific IgE levels and apoB concentrations is shown in Table 1. PAF-AH activities were plotted as a function of apoB concentrations. Plasma PAF-AH activity was strongly correlated with the plasma concentrations of apoB $\left(\mathrm{r}^{2}=0.59, \mathrm{P}<0.0001\right)$ (Figure 1$)$.

\section{Discussion}

Recently, we reported that in patients with acute allergic reactions, blood PAF levels correlated with severity of anaphylaxis. Patients with the highest levels of circulating PAF had more severe reactions and, conversely, those with lowest PAF levels had least severe reactions [6]. PAF-AH activity correlated inversely with PAF levels and patients with the lowest levels of PAF-AH were at highest risk of 
Table 1 PAF-AH, peanut-specific IgE and ApoB concentrations in patients with peanut allergy

\begin{tabular}{cccc}
\hline & $\begin{array}{c}\text { PAF-AH } \\
\text { nmol/min/ml }\end{array}$ & $\begin{array}{c}\text { Peanut-specific } \\
\text { IgE KU/L }\end{array}$ & ApoB mg/dl \\
\hline Mean & 25.18 & 110.5 & 50.51 \\
Standard deviation & 5.67 & 270.60 & 17.17 \\
Standard error & 0.7150 & 34.09 & 2.163 \\
Lower 95\% Cl of mean & 23.75 & 42.39 & 46.18 \\
Upper 95\% Cl of mean & 26.61 & 178.70 & 54.83 \\
\hline
\end{tabular}

severe or fatal anaphylaxis [6]. The odds ratio for patients with severe anaphylaxis vs patients with mild - moderate reactions was 27.0 (95\% CI, 4.2-175.5; 2 tailed $\mathrm{P}=0.00005$ for uncorrected Chi-square) [17]. An odds ratio of 27.0 suggests that patients with the lowest levels of PAF-AH activity were 27.0 times more at risk of severe or fatal anaphylaxis, as compared to patients with normal levels of PAF-AH activity. These and other studies [18] suggest that PAF-AH deficiency predisposes to severe anaphylaxis.

PAF is a potent pro-inflammatory phospholipid messenger which acts via a trans-membrane G-protein coupled PAF receptor [11]. The production of PAF is tightly regulated by both synthetic and degradative processes. Whereas synthesis of PAF in activated cells involves at least 2 enzymes, an arachidonate-specific phospholipase $\mathrm{A}_{2}\left(\mathrm{PLA}_{2}\right)$ and acetyl-CoA-lyso-PAF acetyltransferase, the degradation of PAF to the biologically inactive form, lyso-PAF, is accomplished by the enzyme PAF-AH. The most likely function of PAF-AH may be that of a safety mechanism to limit the levels of PAF [19].

In contrast to proinflammatory phospholipases [20,21], PAF-AH is an anti-inflammatory phospholipase that occurs as a plasma isoform complexed mainly with LDL. In a cohort of 240 normolipidemic individuals, plasma PAF-AH activity was strongly correlated with the plasma concentration of LDL [22]. Among normolipidemic individuals, treatment with lovastatin and fenofibrates resulted

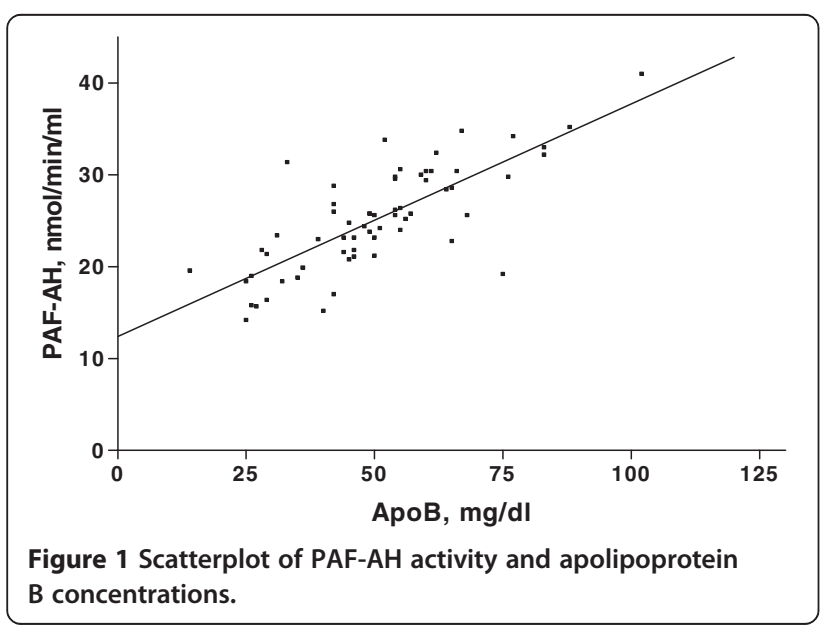

in proportionate decreases in plasma PAF-AH activity and LDL concentrations [22,23]. Removal of LDL from the circulation may determine the clearance rate of PAF-AH, modulating the activity of PAF-AH in blood, and thereby influencing the level of PAF [22].

In this study, our aim was to investigate whether PAF$\mathrm{AH}$ activity correlates with apoB, the main surface protein on LDL particles, in patients with peanut allergy. We did find a linear relationship between serum PAF-AH and apoB concentrations throughout the range of PAF-AH activities, in a pediatric patient population. Complex formation with lipoproteins, especially LDL, may, therefore, be an important determinant of PAF-AH activity. Dietary or pharmacologic strategies to lower LDL may have the unintended consequence of altering PAF-AH activity. In particular, lowering LDL levels pharmacologically in patients at risk for anaphylaxis may lower PAF-AH activity in these patients as well, inadvertently leading to an increased risk of severe or fatal anaphylaxis. It remains to be seen if the results reported for a pediatric age group can be extended to adult patients who are most likely to be using lipid lowering drugs. A study of the relationship between use of lipid lowering drugs to severity of anaphylaxis is currently in progress.

\section{Abbreviations}

apoB: Apolipoprotein B; LDL: Low density lipoproteins; PAF-AH: Platelet activating factor acetylhydrolase; PAF: Platelet activating factor; PLA 2 : Phospholipase $\mathrm{A}_{2}$.

\section{Competing interests}

Peter Vadas has been granted US Patent 8562982: Use of platelet activating factor acetylhydrolase as a biomarker for anaphylaxis.

\section{Authors' contributions}

BP carried out the immunoturbidimetric studies. AA participated in drafting the manuscript. PV designed the studies, carried out the statistical analysis and drafted the manuscript. All authors read and approved the final manuscript.

\section{Funding}

This work was supported by an unrestricted grant to Dr. Peter Vadas from the National Peanut Board.

Received: 6 January 2014 Accepted: 31 March 2014 Published: 28 April 2014

\section{References}

1. Yost CC, Weyrich AS, Zimmerman GA: The platelet activating factor (PAF) signaling cascade in systemic inflammatory responses. Biochimie 2010, 92(6):692-697.

2. Miwa M, Miyake T, Yamanaka T, Sugatani J, Suzuki Y, Sakata S, Araki Y, Matsumoto M: Characterization of serum platelet-activating factor (PAF) acetylhydrolase: correlation between deficiency of serum PAF acetylhydrolase and respiratory symptoms. J Clin Invest 1988, 82:1983-1991.

3. Imaizumi TA, Stafforini DM, Yamada Y, McIntyre TM, Prescott SM, Zimmerman GA: Platelet-activating factor: a mediator for clinicians. J Intern Med 1995, 238:5-20.

4. Arias K, Baig M, Colangelo M, Chu D, Walker T, Goncharova S, Coyle A, Vadas P, Waserman S, Jordana M: Concurrent blockade of plateletactivating factor and histamine prevents life-threatening peanut induced anaphylactic reactions. J Allergy Clin Immunol 2009, 124:307-314.

5. Ishii S, Kuwaki T, Nagase T, Maki K, Tashiro F, Sunaga S, Cao WH, Kume K, Fukuchi Y, Ikuta K, Miyazaki J, Kumada M, Shimizu T: Impaired anaphylactic responses with intact sensitivity to endotoxin in mice lacking a platelet-activating factor receptor. J Exp Med 1998, 187:1779-1788. 
6. Vadas P, Gold M, Perelman B, Liss GM, Lack G, Blyth T, Simons FE, Simons KJ, Cass D, Yeung J: Platelet-activating factor, PAF acetylhydrolase, and severe anaphylaxis. N Engl J Med 2008, 358:28-35.

7. Vadas P, Perelman B, Liss G: Platelet-activating factor, histamine, and tryptase levels in human anaphylaxis. J Allergy Clin Immunol 2013, 131:144-149.

8. Vadas P, Perelman B: Effect of epinephrine on platelet-activating-factorstimulated human vascular smooth muscle cells. J Allergy Clin Immunol 2012, 129:1329-1333.

9. Yanoshita R, Kudo I, Ikizawa K, Chang HW, Kobayashi S, Ohno M, Nojima S, Inoue K: Hydrolysis of platelet activating factor and its methylated analogs by acetylhydrolases. J Biochem 1988, 103:815-819.

10. Stafforini DM, Carter ME, Zimmerman GA, McIntyre TM, Prescott SM: Lipoproteins alter the catalytic behavior of the platelet-activating factor acetylhydrolase in human plasma. Proc Natl Acad Sci 1989, 86:2393-2397.

11. Karasawa K, Harada A, Satoh N, Inoue K, Setaka M: Review: plasma platelet activating factor-acetylhydrolase (PAF-AH). Prog Lipid Res 2003, 42:93-114.

12. Stafforini DM, Mclntyre TM, M Carter E, Prescott SM: Human plasma platelet-activating factor acetylhydrolase association with lipoprotein particles and role in the degradation of platelet activating factor. $J$ Biol Chem 1987, 262:4215-4222

13. Caslake MJ, Packard CJ, Suckling KE, Holmes SD, Chamberlain P, Macphee $\mathrm{CH}$ : Lipoprotein-associated phospholipase $\mathrm{A}_{2}$, platelet-activating factor acetylhydrolase: a potential new risk factor for coronary artery disease. Atherosclerosis 2000, 150:413-419.

14. Zhang B, Fan P, Shimoji E, Itabe H, Miura S, Uehara Y, Matsunaga A, Saku K: Modulating effects of cholesterol feeding and simvastatin treatment on platelet-activating factor acetylhydrolase activity and lysophosphatidylcholine concentration. Atherosclerosis 2006, 186:291-301.

15. Stafforini DM, Tjoelker LW, McCormick SP, Vaitkus D, McIntyre TM, Gray PW, Young SG, Prescott SM: Molecular basis of the interaction between plasma platelet-activating factor acetylhydrolase and low density lipoprotein. J Biol Chem 1999, 274:7018-7024.

16. Fielding PE, Fielding CJ: Dynamics of lipoprotein transport in the human circulatory system. In Biochemistry of Lipids, Lipoproteins and Membranes. 4th edition. Edited by Vance DE, Vance JE. Amsterdam: Elsevier; 2002:527-552.

17. Vadas P, Liss G: Anaphylaxis: clinical patterns, mediator release and severity. J Allergy Clin Immunol 2013.

18. Brown SG, Stone SF, Fatovich DM, Burrows SA, Holdgate A, Celenza A Coulson A, Hartnett L, Nagree Y, Cotterell C, Isbister GK: Anaphylaxis: Clinical patterns, mediator release, and severity. J Allergy Clin Immunol 2013, 132(5):1141-1149.

19. Gardner AA, Reichert EC, Topham MK, Stafforini DM: Identification of a domain that mediates association of platelet-activating factor acetylhydrolase with high density lipoprotein. J Biol Chem 2008, 283:17099-17106.

20. Triggiani M, Granata F, Giannattasio G, Marone G: Secretory phospholipases A2 in inflammatory and allergic diseases: not just enzymes. J Allergy Clin Immunol 2005, 116:1000-1006.

21. Vadas P, Browning J, Edelson J, Pruzanski W: Extracellular phospholipase A2 expression and inflammation: the relationship with associated disease states. J Lipid Mediat 1993, 8:1-30.

22. Guerra R, Zhao B, Mooser V, Stafforini DM, Johnston JM, Cohen JC: Determinants of plasma platelet activating factor acetylhydrolase: heritability and relationship to plasma lipoproteins. J Lipid Res 1997, 38:2281-2288

23. Eisaf M, Tselepis AD: Effect of hypolipidemic drugs on lipoprotein-associated platelet activating factor acetylhydrolase. Implication for atherosclerosis. Biochem Pharmacol 2003, 66:2069-2073.

doi:10.1186/1710-1492-10-20

Cite this article as: Perelman et al:: Relationship between platelet activating factor acetylhydrolase activity and apolipoprotein B levels in patients with peanut allergy. Allergy, Asthma \& Clinical Immunology 2014 10:20.

\section{Submit your next manuscript to BioMed Central and take full advantage of:}

- Convenient online submission

- Thorough peer review

- No space constraints or color figure charges

- Immediate publication on acceptance

- Inclusion in PubMed, CAS, Scopus and Google Scholar

- Research which is freely available for redistribution 